\title{
Research Support in New Zealand University Libraries
}

Jess Howie, University of Waikato, Hamilton, New Zealand

ORCID - https://orcid.org/0000-0002-3164-5034

Twitter - @JesselizH

Hinerangi Kara, University of Waikato, Hamilton, New Zealand

ORCID - https://orcid.org/0000-0003-0860-6077 


\section{Abstract}

Researcher-facing librarians in New Zealand are providing guidance across more of the research lifecycle than ever before in response to an increasingly complex scholarly ecosystem. This research explored the development of research support through survey responses from all eight New Zealand University Libraries. From the responses it was possible to ascertain the level of services offered or planned in the four key areas of research impact, Research Data Management, scholarly communication and Kaupapa Māori research. Skills gaps and barriers to service development were also identified. Comparison with an earlier study revealed that research impact and Research Data Management services have developed well over the last 6 years. A good level of maturity was identified in scholarly communication services but support for Kaupapa Māori research was identified as an area for development. Barriers to service development included lack of resourcing and low recognition of library value from the wider institution.

\section{Keywords}

Research support, scholarly communication, research impact, bibliometrics, altmetrics, research data management, workforce planning, collaboration, job titles, Kaupapa Māori research, indigenous library services, cultural competence, postcolonial universities, library services, librarians, librarianship 


\section{Introduction}

The scholarly ecosystem is changing, and university libraries are increasingly acting as partners and change agents in response. The explosion of data has necessitated new and refined methods for management and sharing. The importance of global rankings and research assessment activities is rising, as is the need for researchers to self-promote and ensure attribution. The growing focus on Open Access and the resulting expansion of predatory and unethical publishing practices is changing scholarship forever. However, change creates opportunity, and librarians have always been good at adapting to change, as evidenced by their response to the seismic shift of format from print to digital. These evolving circumstances have spurred the development of new areas of service for libraries as they move to add value throughout the research lifecycle, assisting not just in the curation of content, but in the creation and management of it. New Zealand makes a unique context for the development of these services, given our position as a bi-cultural, postcolonial nation on the periphery of western academia..

The purpose of this investigation was to explore the nature and extent of research support services in the eight New Zealand university libraries. It also examined the factors influencing the development and delivery of these services. The four foci were services relating to research impact, research data management (RDM), scholarly communication and Kaupapa Māori research. For each of these areas we hoped to ascertain what level of services were being offered, or were planned, how those services were being developed, what skills gaps existed and what barriers were perceived to inhibit their development.

The survey instrument used two prior studies exploring similar areas - Haddow and Mamtora (2017), which focussed on Australian Universities, and Corrall, Kennan, and Afzal (2013), whose global sample included university libraries in both Australia and New Zealand. For those items common to Haddow and Mamtora (2017) (research impact/bibliometrics), we were able to benchmark against services identified as being offered in Australia. For those items in 
common with Corrall et al. (2013), (research impact/bibliometric and Research Data Management) we were able to identify changes in New Zealand university library research services since 2012. The two new foci; scholarly communication and Kauapa Māori research, were added as areas which have seen little attention in the literature at this point and are of critical importance in the New Zealand context. It is hoped the results as a whole will offer a snapshot of the research support landscape in New Zealand university libraries, and provide a basis for future research, as well as informing decisions around future directions. 


\section{Literature review}

The scholarly communication landscape has seen dramatic change in the last 10 years; Open Access has increased in importance, the reproducibility crisis has come to light, predatory publishing practices have become more commonplace, and funders and publishers are beginning to place their own demands on researchers. Underpinning this transformation is the emergence of new research tools and technologies, an explosion in the amount of data being produced (and the associated requirements for its management), and global and national directions on transparency of research processes and outcomes. This has prompted a dramatic transformation in the way librarians support research. Library research support has seen considerable attention in academic library literature in response to these changes (Borrego, Ardanuy, \& Urbano, 2018; Haddow \& Mamtora, 2017; Jaguszewski \& Williams, 2013; Kennan, Corrall, \& Afzal, 2014; Koltay, 2019; Lang, Wilson, Wilson, \& Kirkpatrick, 2018; McNab \& Tattersall, 2017; Willson, Merrick, \& Genoni, 2006), however the New Zealand context has been addressed only at a cursory level. Keller (2015) observes the force with which Australian university libraries see themselves as 'genuine partners in research' (p.75), and that through their research support offerings, they improve their standing within their wider institutions, but it is uncertain as to whether New Zealand is heading in the same direction.

Universities comprise a huge part of the research landscape in New Zealand, accounting for $65 \%$ of New Zealand's basic research and 25\% of applied research (by expenditure) and housing $70 \%$ of the country's total researchers, including postgraduate research students (Statistics New Zealand, 2017). The Performance Based Research Funding (PBRF) model was initiated in 2002 with the goal of encouraging and rewarding research excellence. The process involves active researchers in New Zealand universities compiling and submitting portfolios of their research for evaluation by discipline specific panels. The results help to informthe share of funding each university receives from the government (currently a pool of NZD\$315 
million). Research degree completion (25\% of the fund) and external research income (20\% of the fund) are also factored into this system (Tertiary Education Commission, 2019). In addition, researchers compete for grants from major funding bodies such as the Marsden Fund and the Health Research Council. As a result, New Zealand researchers are strongly incentivised to produce both high impact research and quality research postgraduates. Simultaneously, Kaupapa Māori research (research by, for, with, or about the indigenous people of New Zealand), continues to grow in strength and importance in the New Zealand research landscape, yet there is growing concern around the extent to which the research system limits or enables this (McAllister, Kidman, Rowley, \& Theordore, 2019; Roa, Beggs, Williams, \& Moller, 2009; Smith, 2012). Other challenges include the arising crises in reproducibility and the need to collaborate with both industry and international partners. The strong focus on research productivity and funding places a heavy burden on researchers. As a result, they rely heavily on support services such as libraries for administrative assistance, skills development and advice. Conversely, New Zealand university libraries have a responsibility to provide advocacy on research issues and safe spaces for those seeking information and advice. However, research indicates that many library research support services are underused and undervalued in New Zealand (Ithaka S+R, 2018).

Library expertise in bibliometrics is rooted in collection development activities such as assessment, and as such is not technically new (Bladek, 2014; Gorraiz, Wieland, \& Gumpenberger, 2012). However, as research assessment exercises such as PBRF have developed and increased in importance, librarians have identified opportunities to leverage their resources and expertise for new purposes. The rise in popularity of university ranking systems and range of new and emerging metrics have also been drivers for this. In response, libraries across the world have worked to align themselves with the research evaluation model in their country (Haddow \& Mamtora, 2017). In their investigation, Corrall et al. (2013) 
focussed primarily on bibliometrics, whereas Haddow and Mamtora extended their iteration of the survey to include altmetrics. In their 2013 study, Corrall et al. identified that library involvement with bibliometric support was growing. The follow-up study by Haddow and Mamtora (2017) and another study undertaken by the Primary Research Group (2017) confirmed further growth. Collaboration with other units within the university has been identified by some as a key factor in success (Auckland, 2012; Bladek, 2014; Haddow, 2012), as has competency and confidence on the part of the librarians involved (Cox, Gadd, Petersohn, \& Sbaffi, 2017). Both Corrall et al. (2013) and Haddow and Mamtora (2017) identified low engagement on the part of the wider institutions as constraints to the development of bibliographic services. Petersohn (2014); Petersohn and Heinze (2017) link libraries' involvement with research assessment with the 'audit culture' brought on by the changing research environment, concluding that bibliometric services now constitute a new professional field in librarianship

Another outcome of the changing scholarly landscape is the emergence of Research Data Management (RDM) as an area of service. This can be attributed to a number of factors, including the advancement of computing infrastructure, the availability and scale of data (including 'Big Data'), and the increasing demand, particularly from funders, for transparent research practices. These new characteristics have been dubbed Research 2.0 by some scholars (Koltay, 2017, 2019). The fact that librarians are well versed in managing archives, metadata, cataloguing and discovery tools positions them well to add value in the emerging RDM area. Research Data Management has unique importance in the New Zealand context, given that Māori culture is deeply embedded into much research. In light of this, research data, and particularly Māori research data (data that is held by Māori, produced by Māori, or is about Māori and environments they have relationships with) is viewed as living Taonga (treasure or highly prized object) (Te Mana Rauranga, 2016). There is much work happening in New 
Zealand to ensure that Māori data is subject to Māori governance, and treated in culturally appropriate ways, and that those engaging with Kaupapa Māori research need to be aware of these considerations. While prevalent overseas, most major New Zealand funders do not yet require RDM plans as part of the bidding process. Overseas, requirement of such plans has been a key driver of RDM development, particularly in Europe, Australia and America; the present lack of a mandate in New Zealand is impacting progress in the area. There is also currently no clear national agenda, framework or platform to set direction, as there is in Australia. However, some universities are beginning to develop their own policies. A report carried out by Universities New Zealand in 2016 notes the dangers of not engaging with RDM best practice and recommends that libraries, in conjunction with other stakeholders, should lead initiatives to establish RDM services, lest systems become flooded with data that is inaccessible, unusable, unverifiable or stored on volatile media.

Studies have shown steady growth in RDM-related services over time and in a number of contexts (Auckland, 2012; Corrall et al., 2013; Cox, Kennan, Lyon, \& Pinfield, 2017; Cox \& Pinfield, 2013; Haddow \& Mamtora, 2017). From these studies it has become clear that while libraries have been leaders in the RDM space, development has been concentrated in the advisory space, rather than in the technical and infrastructure space (Cox, Kennan, et al., 2017; Hua, Zhuang, Si, Zhou, \& Xing, 2015; Tenopir, Sandusky, Allard, \& Birch, 2014). Cox, Kennan, et al. (2017) found that New Zealand was somewhat behind other countries in some of these facets (for example, partnerships with stakeholders and institutional evaluation of data), but also pointed out that patterns arose in relation to national and funder level frameworks. Those countries with national frameworks like ANDS (Australian National Data Service), tended to have more mature service offerings. Collaboration was found to be a key success factor by almost all authors (Cox, Kennan, et al., 2017; Cox \& Pinfield, 2013; Faniel \& Connaway, 2018; Hua et al., 2015; Tenopir et al., 2017; Wilson, Martinez-Uribe, Fraser, \& 
Jeffreys, 2011), although some pointed out that this can be difficult for libraries for working with non-traditional partners. Leadership (Faniel \& Connaway, 2018; Tenopir et al., 2017) and resourcing (Cox, Kennan, et al., 2017; Cox \& Pinfield, 2013) were also highlighted as factors which could either constrain or enable progress depending on how they were applied. Researcher perceptions and buy-in featured prominently as constraining factors in several studies (Cox, Kennan, et al., 2017; Faniel \& Connaway, 2018). Research data skills have also been explored at length in the literature, with a number of authors highlighting the need for more training (Auckland, 2012; Brown, Wolski, \& Richardson, 2015; Corrall et al., 2013). At the crux of the issue seems to be the question of whether to reassign and retrain existing staff, or recruit staff with the skills needed. This is also tied into the notion of whether to distribute skills and duties, or create specialised roles (Green, Nicholls, Sferdean, \& Akers, 2014).The studies reported mixed results on this front, some pointing out the inconsistencies in development across institutions (Cox, Kennan, et al., 2017). An interesting finding from Tenopir et al. (2017) was that most library directors believed they offered opportunities to learn data skills, yet few staff perceived this to be the case. Overall, the literature reflects a landscape which is growing, but not in a consistent way, with many skills gaps and discrepancies in perception on the part of stakeholders.

Increasingly, there are calls for librarians to become embedded in as many of the phases of the research lifecycle as possible (Auckland, 2012; Mamtora, 2013; Parker, 2012). As such, there are also opportunities for librarians to provide advice in the later stages of research -variously including such activities as publishing, promoting and profile-raising. Libraries' role in the management and oversight of institutional repositories positions them perfectly to offer value in the areas of strategic publishing, Open Access, research promotion and profile enhancement. Yet the Ithaka survey (2018) revealed relatively small numbers of researchers aware that the 
library could help them to understand and negotiate publishing contracts (10\%), determine where to publish to maximise impact (17\%) and assess impact after publication (35\%). When asked how valuable they would find library support for each of these activities the responses indicated that many researchers still didn’t see this as an area of value. On a scale of 1 to 10 where 10 was extremely valuable and 1 was not at all valuable, 51\% rated help with publishing contracts, 48\% for publishing advice and 36\% to assessing impact between 1 and 3 (Ithaka $\mathrm{S}+\mathrm{R}, 2018)$. This highlights a perception gap between librarians and researchers and also serves as a reminder of the importance of outreach. Evidence varies on the extent to which library services have evolved in line with the scholarly communication landscape. Jaguszewski and Williams (2013) identified this as an area of leadership for libraries and the fact that Borrego et al. (2018) found an increase in collaboration reflected in publication might indicate that librarians are increasingly embedding themselves as research partners. Hashim and Abdullah (2015) explored librarians' practices in supporting scholarly communication in Malaysian universities and found that librarians play a number of important roles in both pre and postpublication phases of the research lifecycle including as policy makers, research counsellors and promoters. McNab and Tattersall (2017) highlighted the impact of digital transformation on both the research lifecycle and the nature of research support, producing the research technologist manifesto in response. Multiple authors (Willson et al., 2006; Zhao, 2014) have also pointed out the urgent need for the provision of scholarly publishing literacy in response to the explosion of predatory publishing practices.

It is clear that a major challenge in the New Zealand research landscape is the underrepresentation of Māori in the academic workforce (McAllister, Kidman, Rowley, \& Theordore, 2019) and the resulting lack of diversity in the perspectives and outcomes represented in research. The volume and vitality of Kaupapa Māori research, or lack thereof, 
has direct impacts on outcomes for Māori communities, and institutions’ ability to meet their obligations under Te Tiriti o Waitangi (the Treaty of Waitangi), the founding document of New Zealand (which exalts the notions of partnership and participation, among other things). Kaupapa Māori research is, according to Linda Smith’s definition, ‘... research by Māori, for Māori and with Māori.' (2015, p. 47). Kathy Irwin (1994, as cited in Smith, 2012, p. 186) says that Kaupapa Māori research is "research that is 'culturally safe'; that involves the 'mentorship' of elders; that is currently relevant and appropriate while satisfying the rigour of research; and that is undertaken by a Māori researcher, not a researcher who happens to be Māori’. Graham Smith (1990, as cited in Smith, 2012, p. 187) says "Kaupapa Māori research is

1. Related to 'being Māori’;

2. Is connected to Māori philosophy and principles;

3. Takes for granted the validity and legitimacy of Māori, the importance of Māori language and culture; and

4. Is concerned with 'the struggle for autonomy over our own cultural well-being'”

Kaupapa Māori research is generally talked about as a concept and theory. It is largely concerned with how the research should be conducted, the considerations that position the researcher within the context of their research topic, and defining what Māori knowledge is and its validity in Western knowledge systems. Kaupapa Māori research is a legitimate form of researching Māori knowledge designed to receive, to understand and to report the findings in a way that not only align with Māori values, but attains a level of richness and contextual relevance that would not be possible under a western methodology. This is largely due to the centrality of relationships in Kaupapa Māori research. The preservation of such research paradigms is necessary to properly embed Kaupapa Māori research in New Zealand academic culture. Indeed this is reflected in the ability of students to submit Phd theses in te reo Māori, though it must be acknowledged that this doesn’t happen as much as it should. How do 
Libraries take this into account when devising practical steps to implement adequate and culturally appropriate research and general support services? Cooper et al. (2019) articulates that Indigenous researchers endeavouring to complete research using an Indigenous research model are faced with issues from access to resources in secure locations and with limited availability, to western numbering systems that govern resource location, to the availability of knowledgeable staff. One unique feature of the New Zealand research landscape is Vision Mātauranga, a policy developed by the former Ministry of Research, Science and Technology. Vision Mātauranga aims to 'unlock the innovation potential of Māori knowledge, resources and people’ (2007, p. i), by compelling researchers (both Māori and non-Māori) to understand and leverage aspects of Tikanga (customary systems of values and practices) in their research. While Kaupapa Māori research has seen considerable attention amongst scholars (McAllister et al., 2019; Smith, 2012), there has yet to be any serious research into how libraries could contribute to Kaupapa Māori research in the evolving scholarly communication landscape.

\section{Methodology}

The purpose of the study was to investigate the nature and extent of research support services in New Zealand university libraries. Questions were divided across the four areas of focus, two of which were adaptated from previous studies (research impact/bibliometrics and Research Data Management), and two of which replicated the same format but focussed on the new areas of scholarly communication and Kaupapa Māori research. The new sections followed the same format and questions of original sections where practicable, with a focus on service offerings, partnerships with other units, job titles, staff time, barriers to service development and skills gaps. For questions on services offerings, respondents were asked to indicate whether a given service was offered, planned or not planned. This allowed for some approximation of how much of the planning from 2012 had been realised. Several generic questions designed to generate detailed responses not offered in earlier sections were also included from the previous 
studies. With the repetition of some questions from Corrall's (2013) study, some longitudinal analysis was possible. Similarly, because Haddow and Mamtora's (2017) study had also included Corrall's questions, comparison with responses from Australia was also possible for some questions.

The section broadly labelled ‘bibliometric services' in Corrall's study, and expanded to include bibliometrics and altmetrics under Haddow and Mamtora was recategorised as 'research impact' in order to encompass the full breadth of services available in 2018. Where questions have been used to allow comparison across studies the wording remained unchanged.

The University of Waikato Ethics Committee granted approval for the survey to be conducted. The survey, created in Qualtrics, contained a consent form on the first page. University Librarians at all eight New Zealand Universities were invited to participate and were sent the survey in October 2018 with the request that either they, or one of their staff members responsible for research support, would complete it. There was a $100 \%$ response rate. Responses were exported to Microsoft Excel so they could be compared with the results from the previous surveys. 


\section{Results}

\section{Research impact}

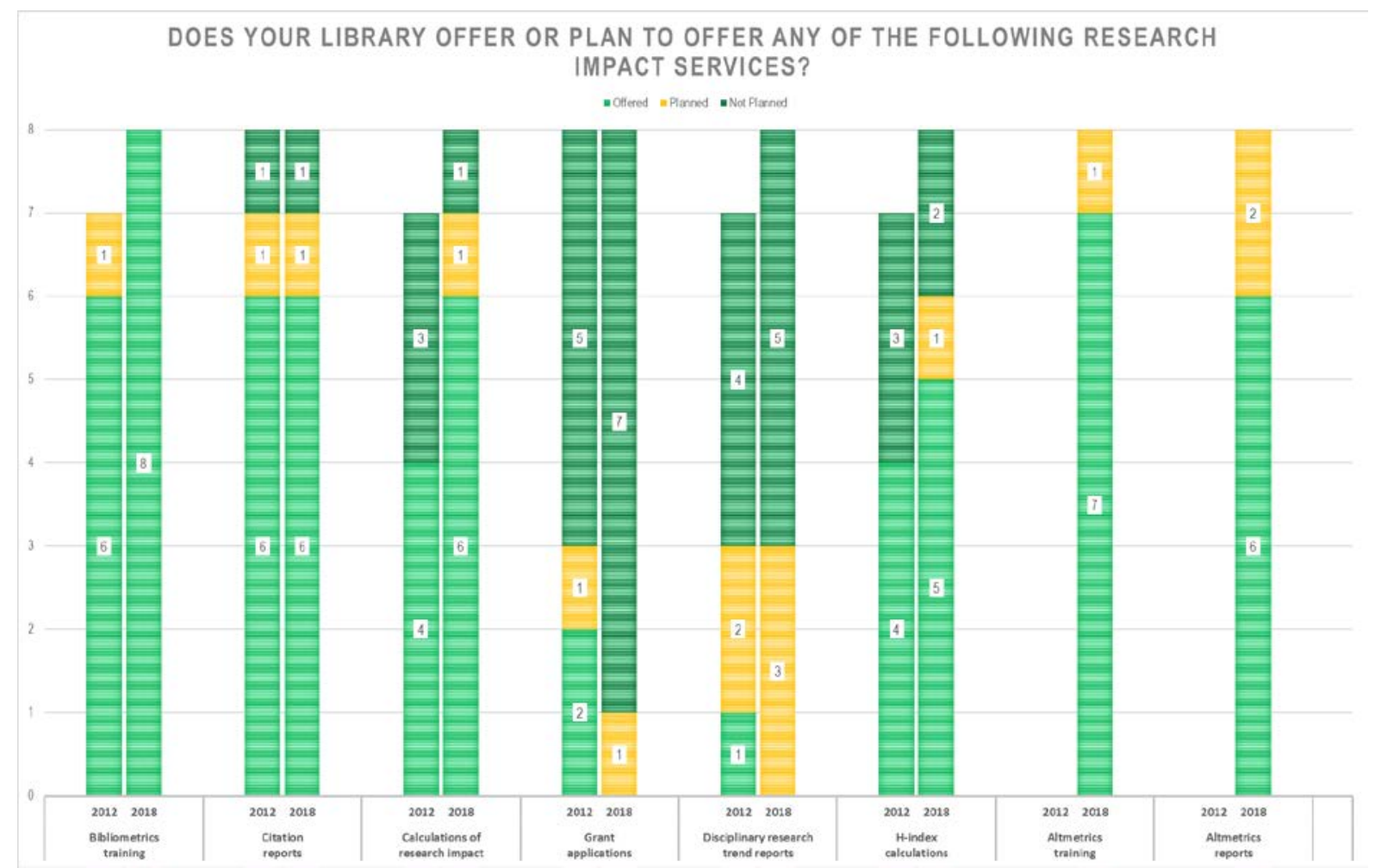

Figure 1 Research impact services

Figure 1 shows the reported change in research impact services between 2012 and 2018. The only service to have declined was grant applications, along with a slight dip in disciplinary research trend reports. From the results, we can conclude that at least some of the early planning for bibliometric training, calculations on research impact and h-index calculations has been realised. Citation reporting showed no change. Offerings and interest in altmetrics remained strong, with all libraries either offering or planning both altmetric training and reporting, slightly more than Australia in 2017 (Haddow \& Mamtora, p. 95). 


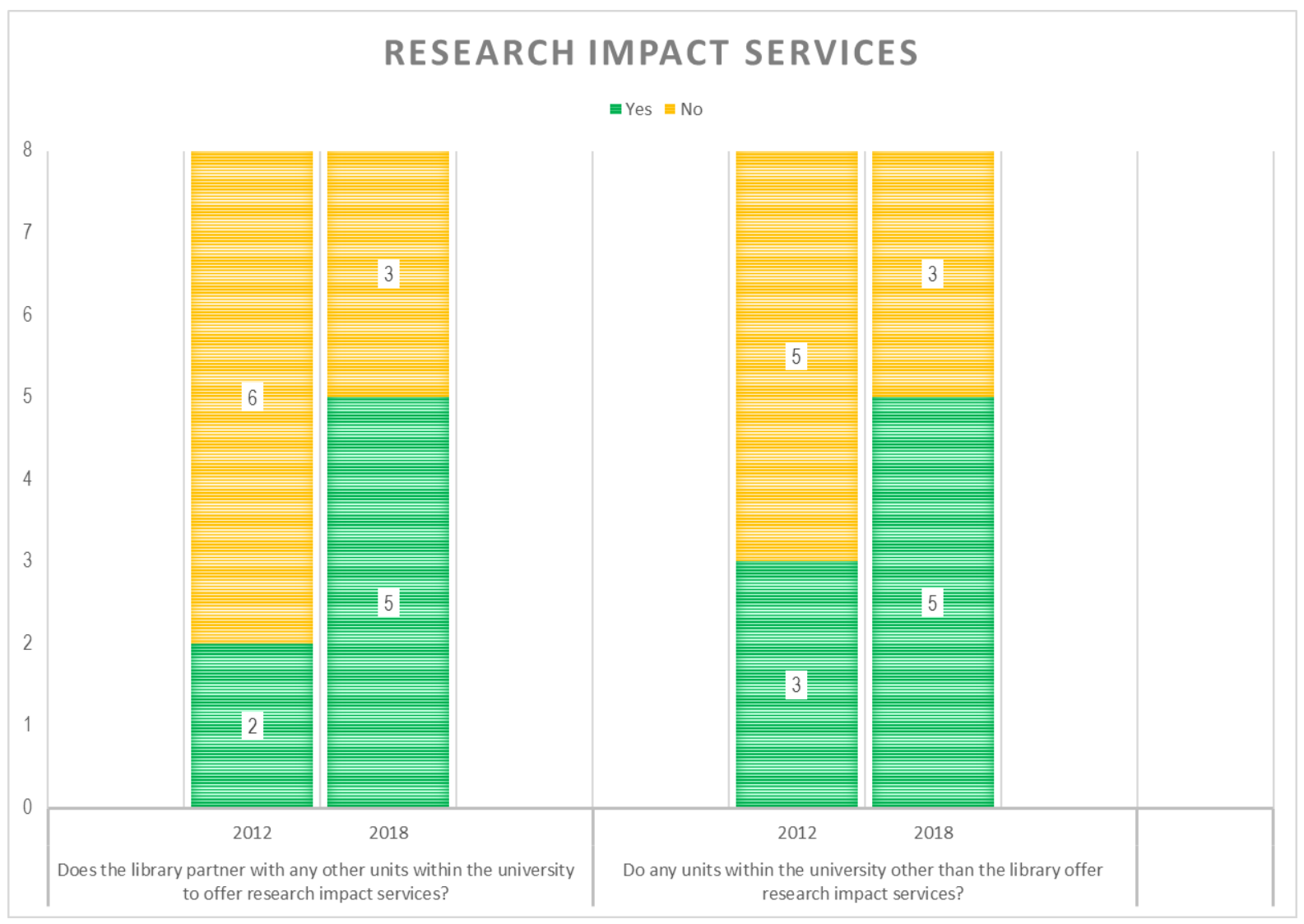

Figure 2 Research impact service partners

Figure 2 shows how libraries were working with other units within their universities. The responses show an increase in the number of libraries working alongside other units within the university to deliver research impact services. The number of other units within the university also offering these services also rose in line with that figure. This reinforces the importance of collaboration andalso serves as a reminder that libraries are not the only support unit operating in this space. Units mentioned by name were research and planning offices, academic services and graduate research units. Some units did respond that this collaboration was occasional in nature. Others noted increasing interest on the part of research offices and equivalent units in non-scholarly impact. 


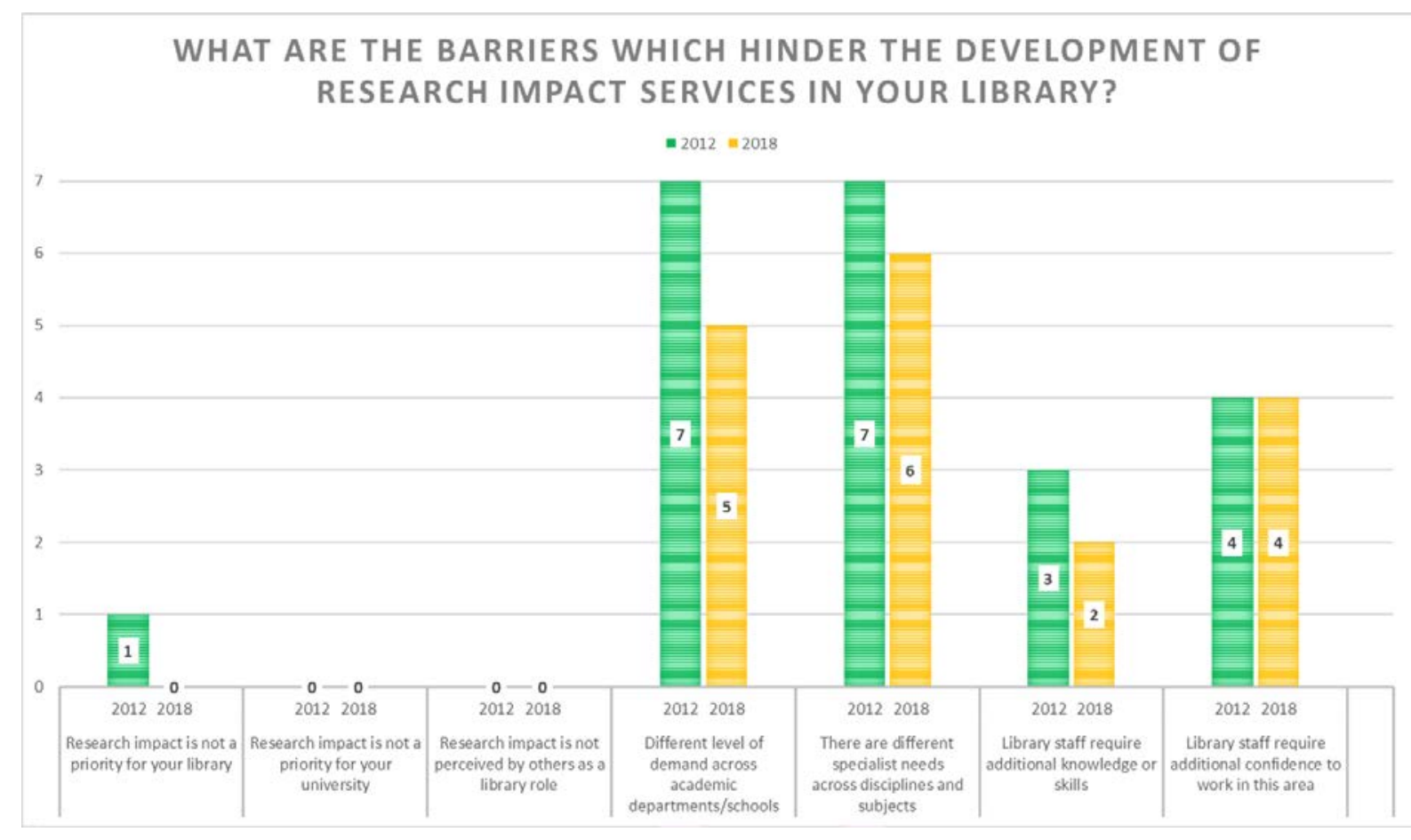

Figure 3 Barriers to research impact services

Overall, barriers to the development of research impact services reduced between 2012 and 2018. The only barrier that saw no change was lack of confidence on the part of library staff. Interestingly, all three iterations of the survey saw respondents comment on a lack of resourcing, in terms of both staff and staff time. Though discipline disparity reduced as a barrier, it still rated highly, with five and six universities respectively affirming different levels of demand and different needs across disciplines as a barrier.From the 'zero' responses, we can infer that research impact does feature on all university agendas, and that the library is seen as a legitimate player in this field. Additionally, the requirement for knowledge or skills was seen as less of a barrier than in the Australian iteration of the study (dropping from $80 \%$ to about half) (Haddow \& Mamtora, 2017). These results point to a healthy future for library involvement with research impact, the main concern being that demand will outstrip supply in some areas. 


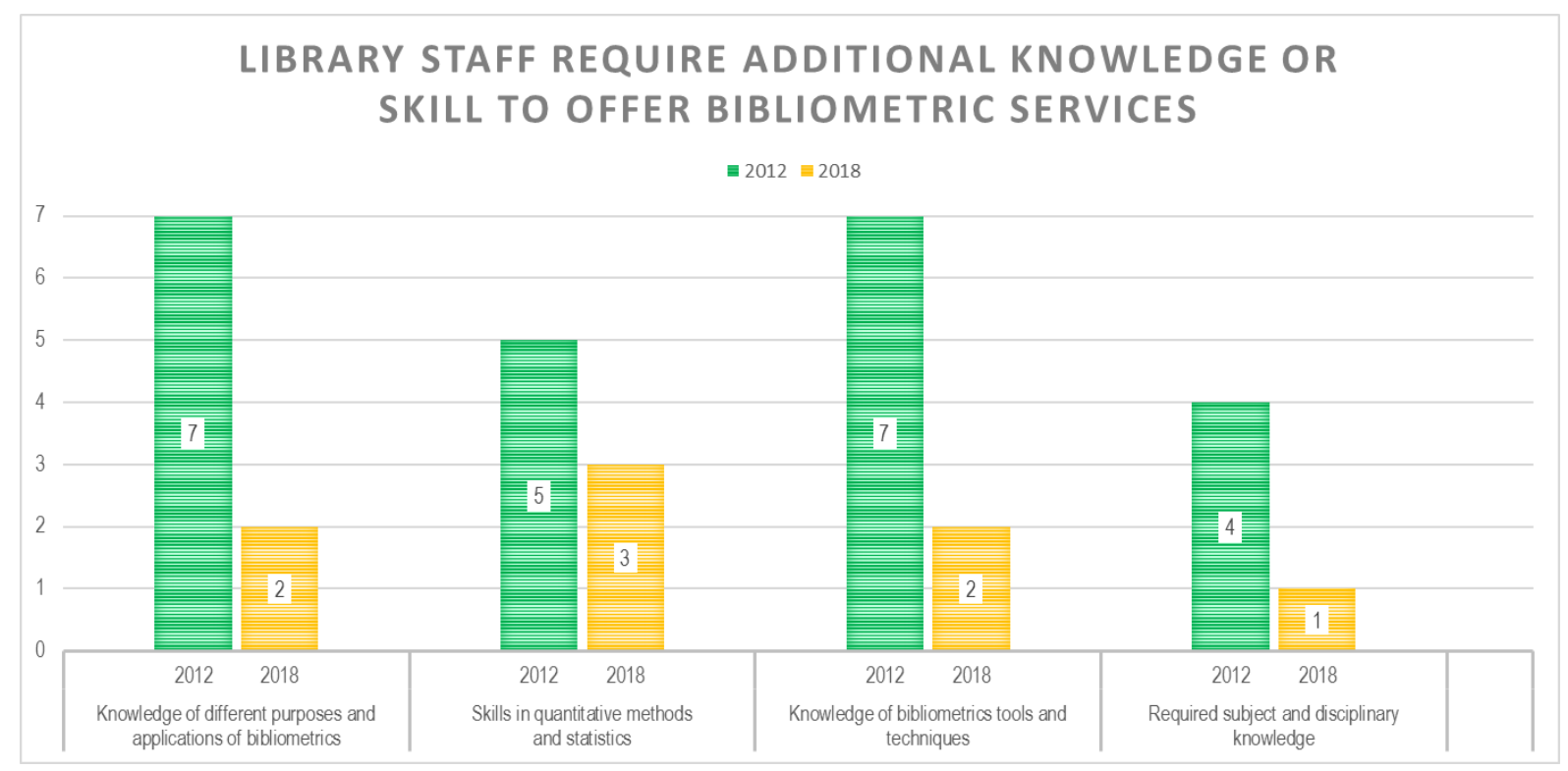

Figure 4 Research impact services and staff skills

A drop in the overall number of respondents who indicated knowledge or skills gaps indicates that capacity is growing in this area. The highest skills gap was in quantitative methods and statistics, and only three universities agreed that this was a factor. From this we can conclude that bibliometric capacity has grown substantially since 2012 and most library staff are well positioned to contribute in this space. 


\section{Research Data Management}

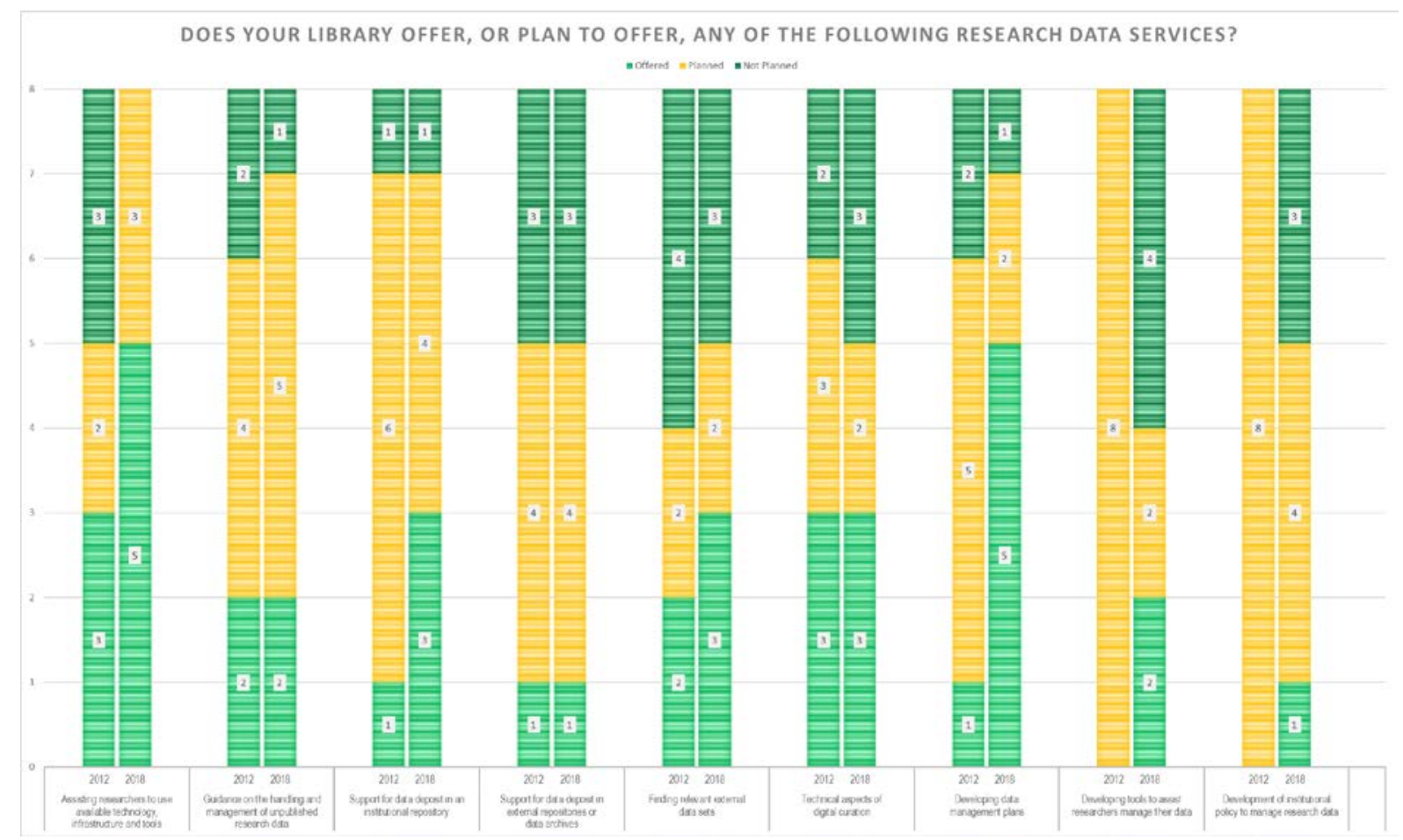

Figure 5 Research Data Management services

Results indicated that research data services in general had developed over time, with all services offered more widely or at least having stayed the same. Interestingly, some services showed an increase in those with no plans to develop the service, namely 'development of institutional policy to manage research data', 'developing tools to assist researchers manage their data' and 'technical aspects of digital creation'. Although all services were offered as widely, or more widely than in 2012, the most widely-offered services were still only offered by five universities, those being 'assisting researchers to use available technology, infrastructure and tools', and 'developing data management plans'. There is considerable planning still to be realised. 


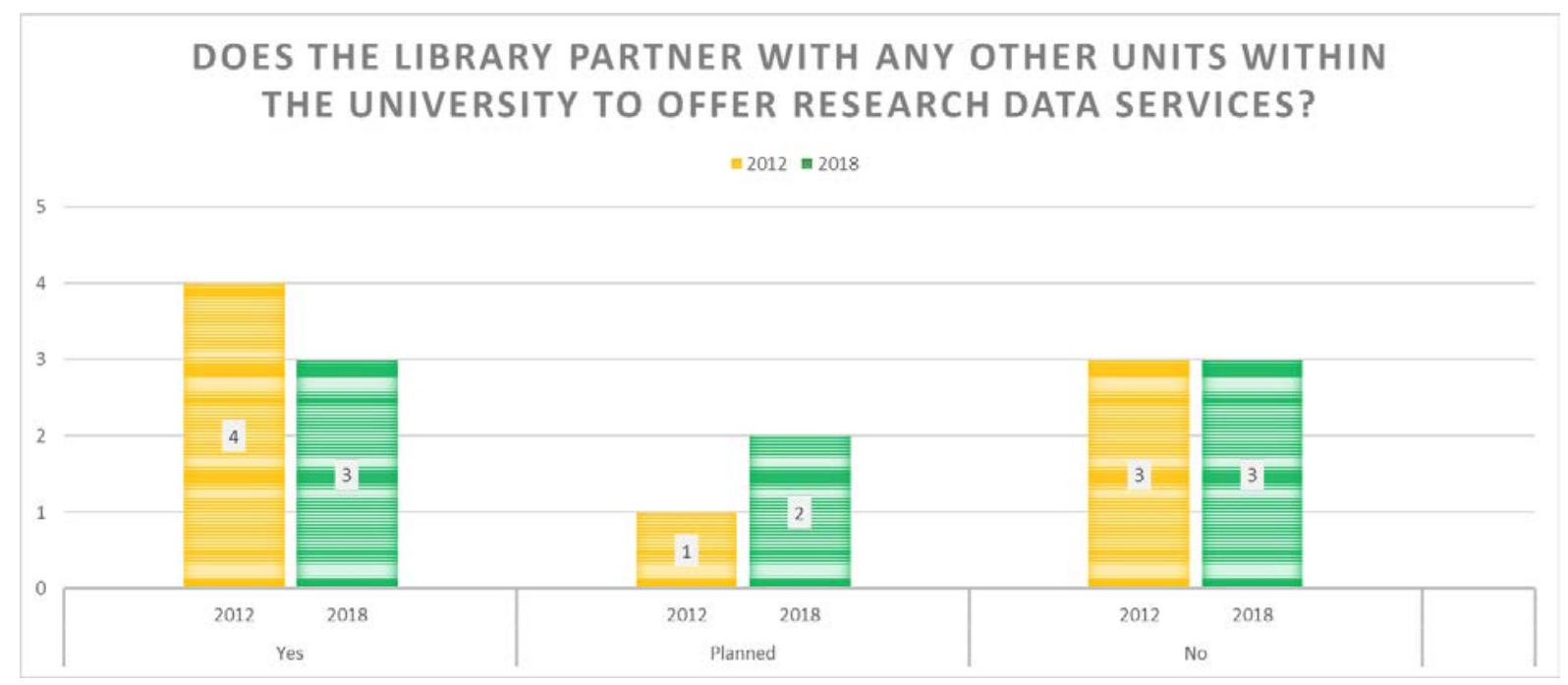

Figure 6 Research Data Management service partners

New Zealand university libraries were divided as to how they were partnering with other units within the university to deliver Research Data Management services. Responses reflected a degree of uncertainty around what was happening in other parts of the university, indicating that there is potential for more collaboration. Around half of the respondents indicated that RDM services were offered elsewhere in the university, such as computing or information technology services.

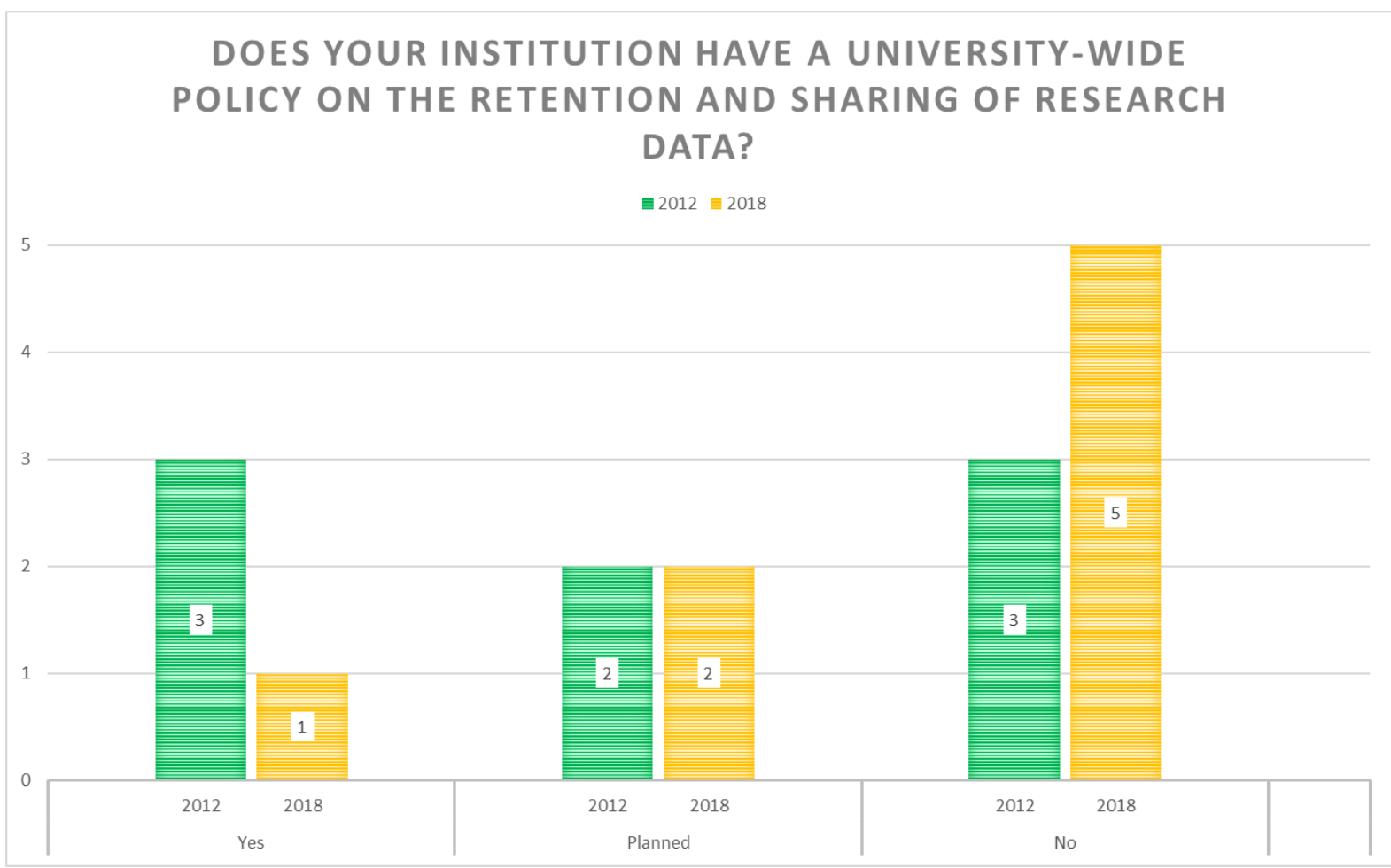


Only one of the eight universities had a university-wide policy on the retention and sharing of research data, with a further two under development. Surprisingly, in 2012 three universities indicated they did have such a policy, which suggests that either the policies have been retired, are under revision, or are otherwise unknown.

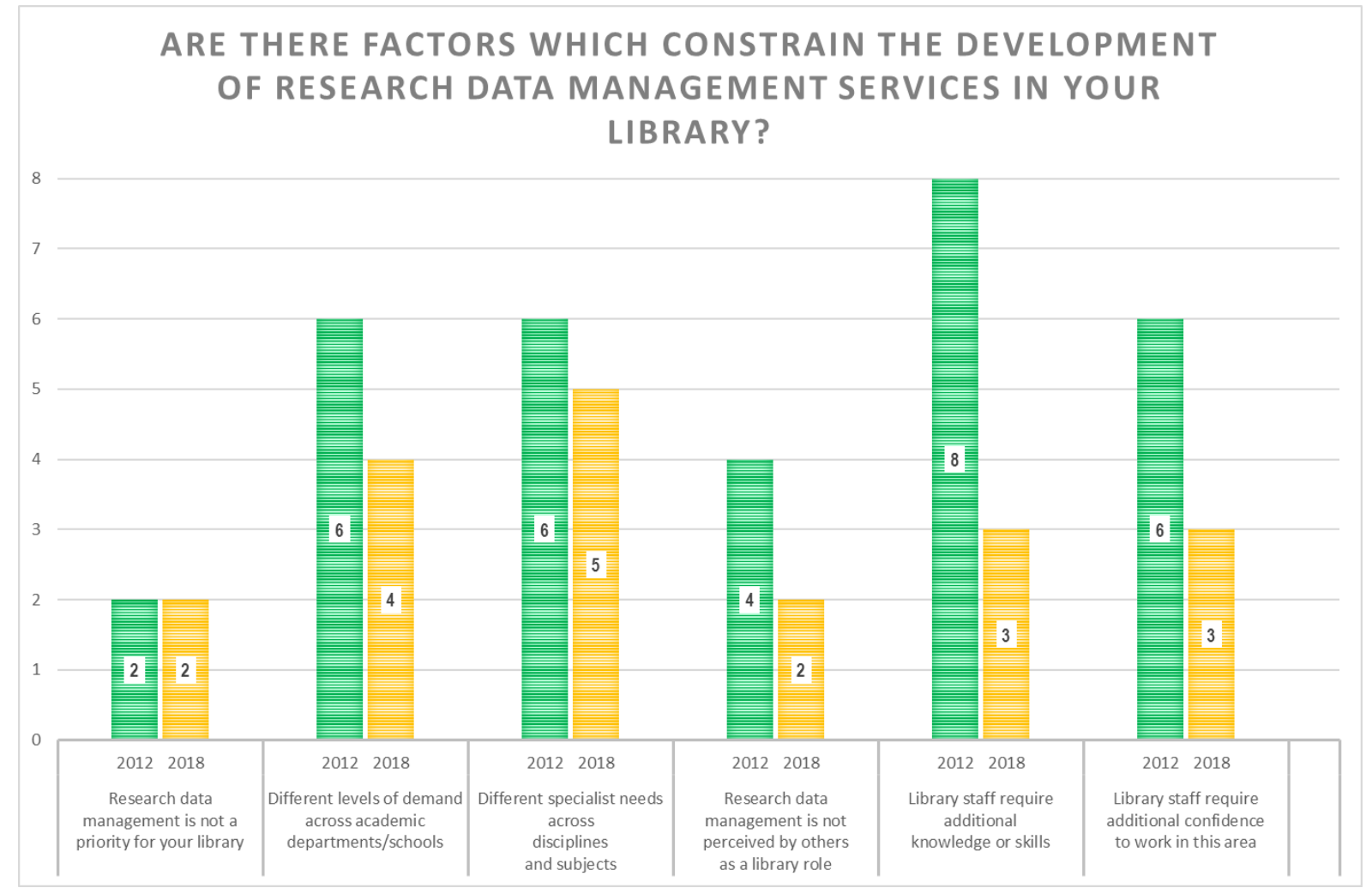

Figure 8 Barriers to Research Data Management services

Interestingly, the results show widespread reduction in constraining factors since 2012. The only factor that had remained constant was 'research data management is not a priority for your library', which rated relatively low, attracting only two responses from universities. The biggest change occurred for 'library staff require additional knowledge or skills', which all universities agreed was a constraining factor in 2012. In 2018 only three identified this as a factor. The results indicate that RDM capacity is building. 
The most commonly-cited further barrier was the lack of a university policy or mandate interesting in light of the fact that there appear to be fewer policies in 2018 than in 2012 as indicated in Figure 7.

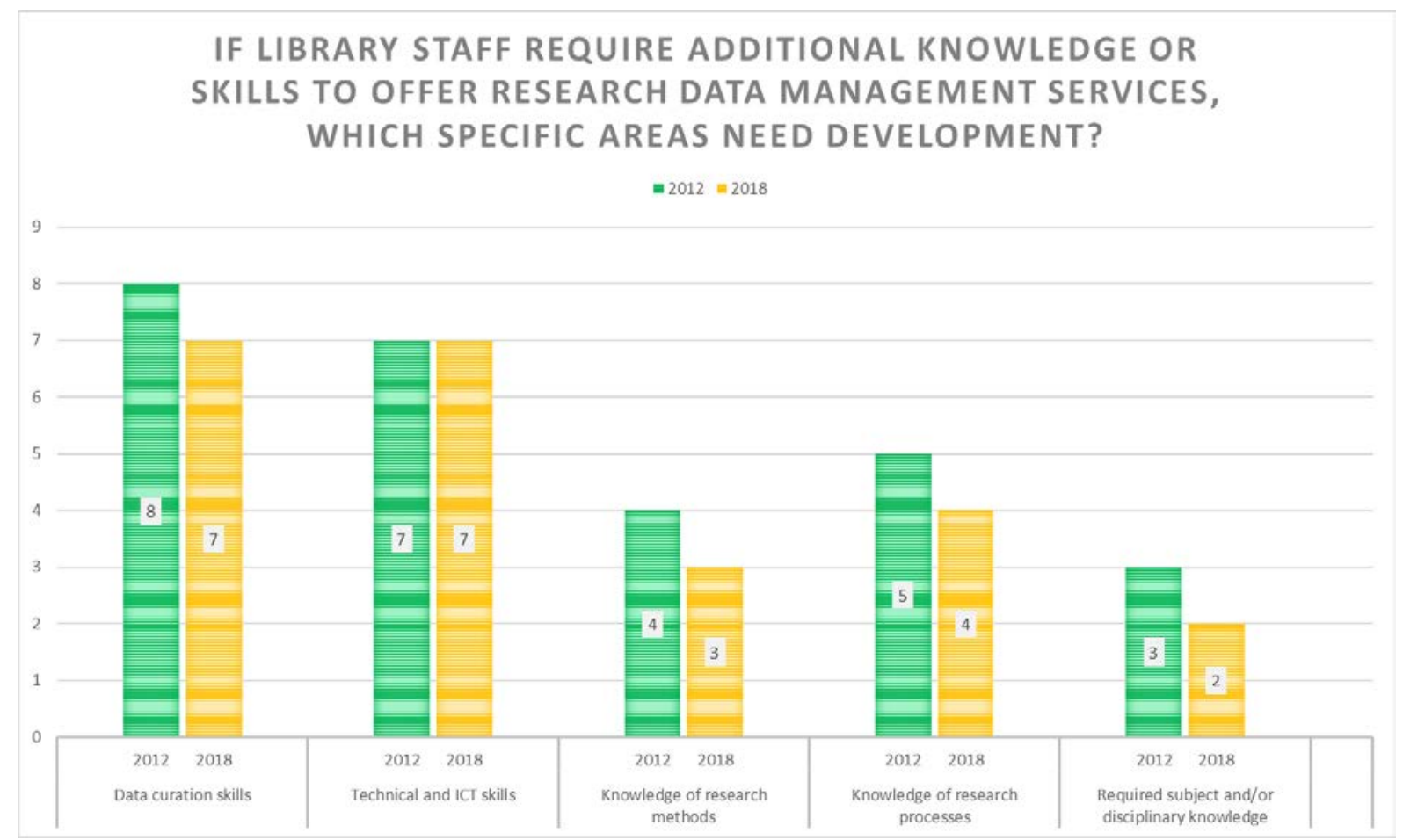

Figure 9 Research Data Management services and staff skills

As with research impact, it would appear that staff capacity is growing in RDM, though not to the same extent. Seven out of eight universities still acknowledge a shortage of data curation, technical and ICT skills. The continued rise in expertise around research methods and processes will be of interest to many in the profession, and indicates that those carrying out research support roles are well versed in the research lifecycle. 


\section{Scholarly communication}

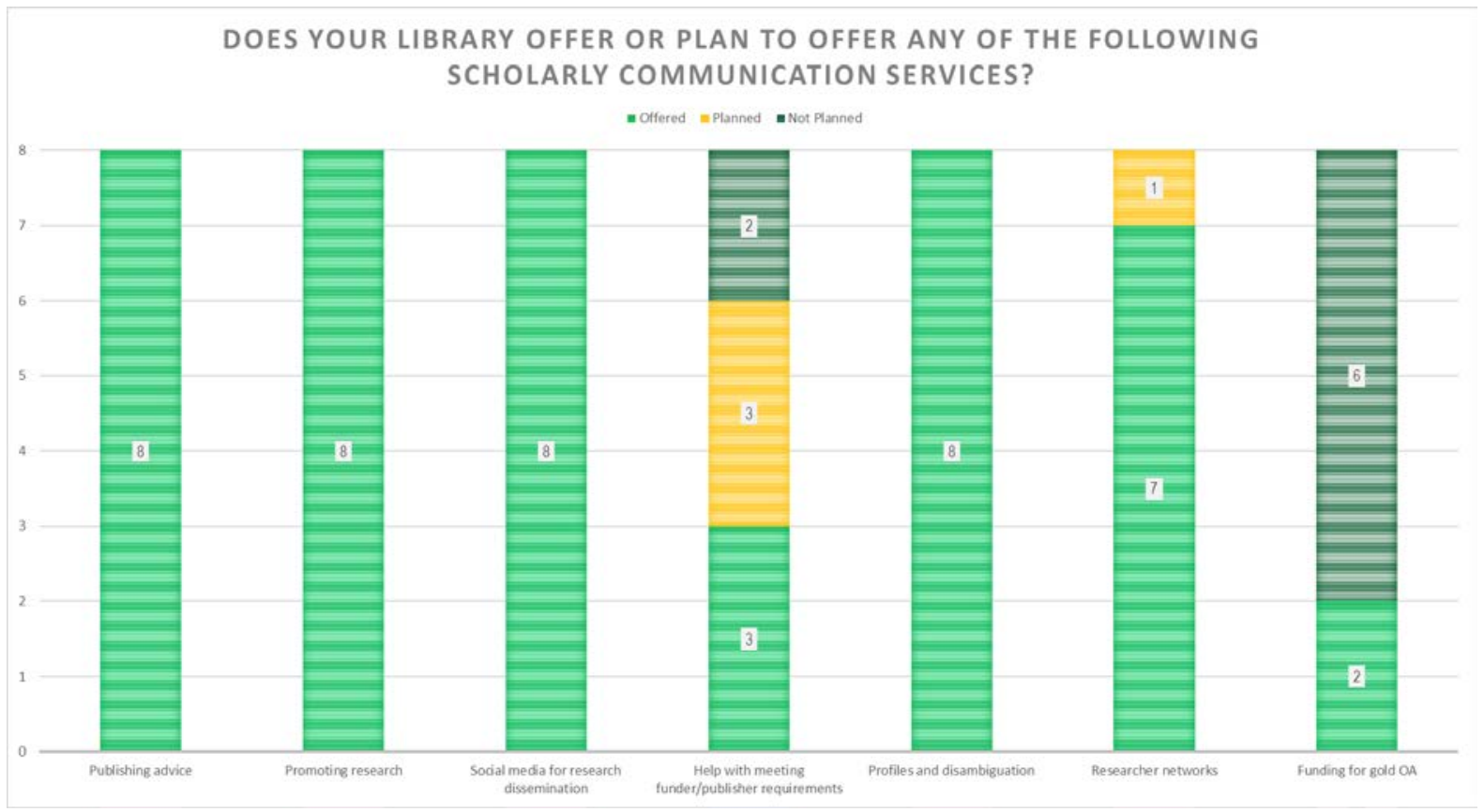

Figure 10 Scholarly communication services

The responses for scholarly communication services revealed a very well developed level of service across the country with publishing, research promotion, social media and profile advice offered across the board. Help with meeting funder/publisher requirements was the only area that varied widely with three universities offering and a further three planning services. Funding for gold Open Access was only offered at two universities and not planned elsewhere, not surprising in the current economic climate. Funding for Article Processing Charges (APCs) was identified by several respondents as an upcoming issue of importance. 


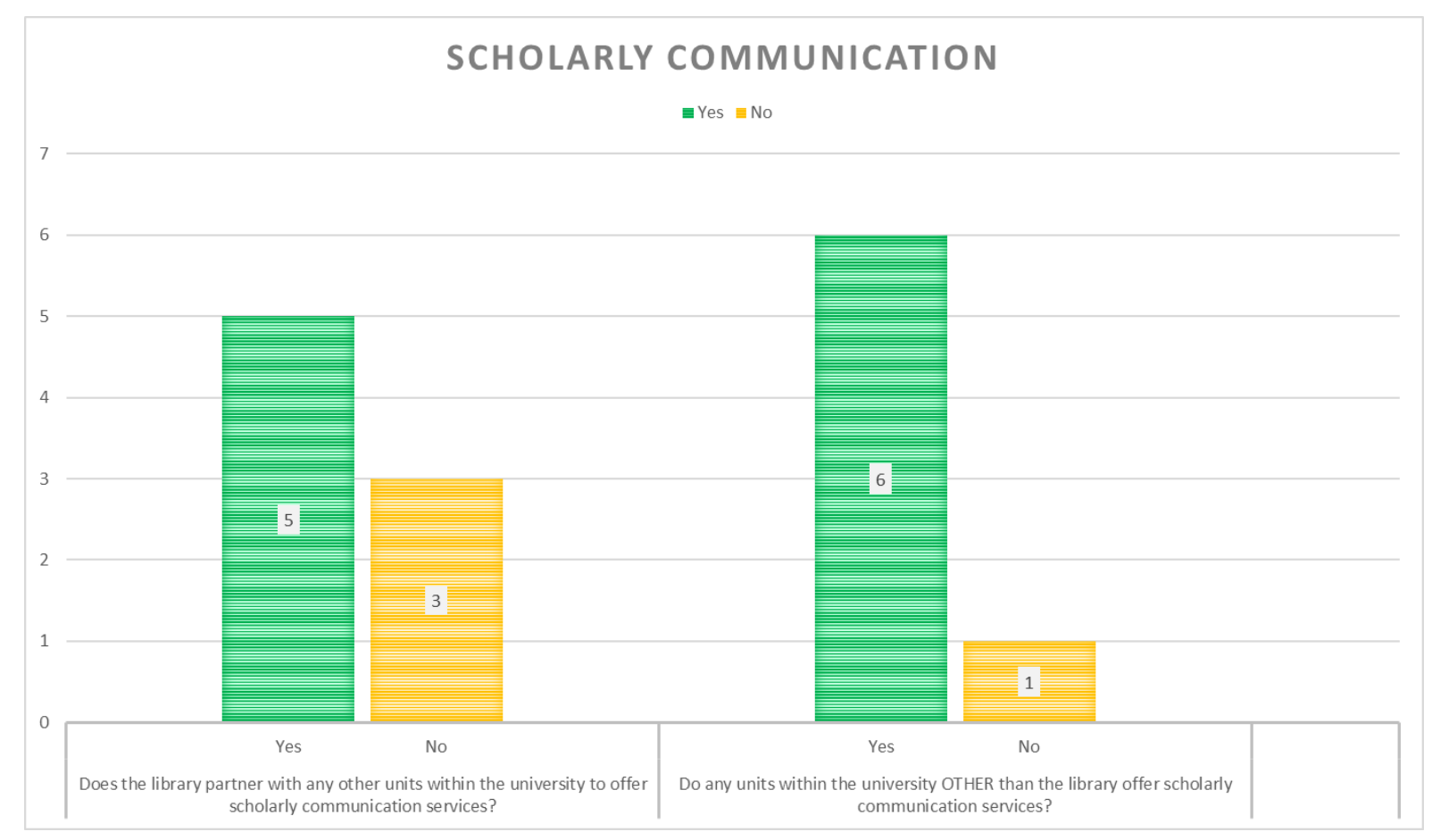

Figure 11 Scholarly communication service partners

Five out of the eight university libraries partner with other units within the university to offer scholarly communication services, with the research office or equivalent being the most usual partner. The communications unit was mentioned by one university, and this is one area where there is a great deal of potential to be realised. Research office or equivalent was the most commonly mentioned other party to be offering scholarly communication services independently from the library, followed by academic services or equivalent. Only one respondent indicated that scholarly communication services were offered independently from the library, indicating that the library is generally collaborating rather than competing with other sources of support in this area. 


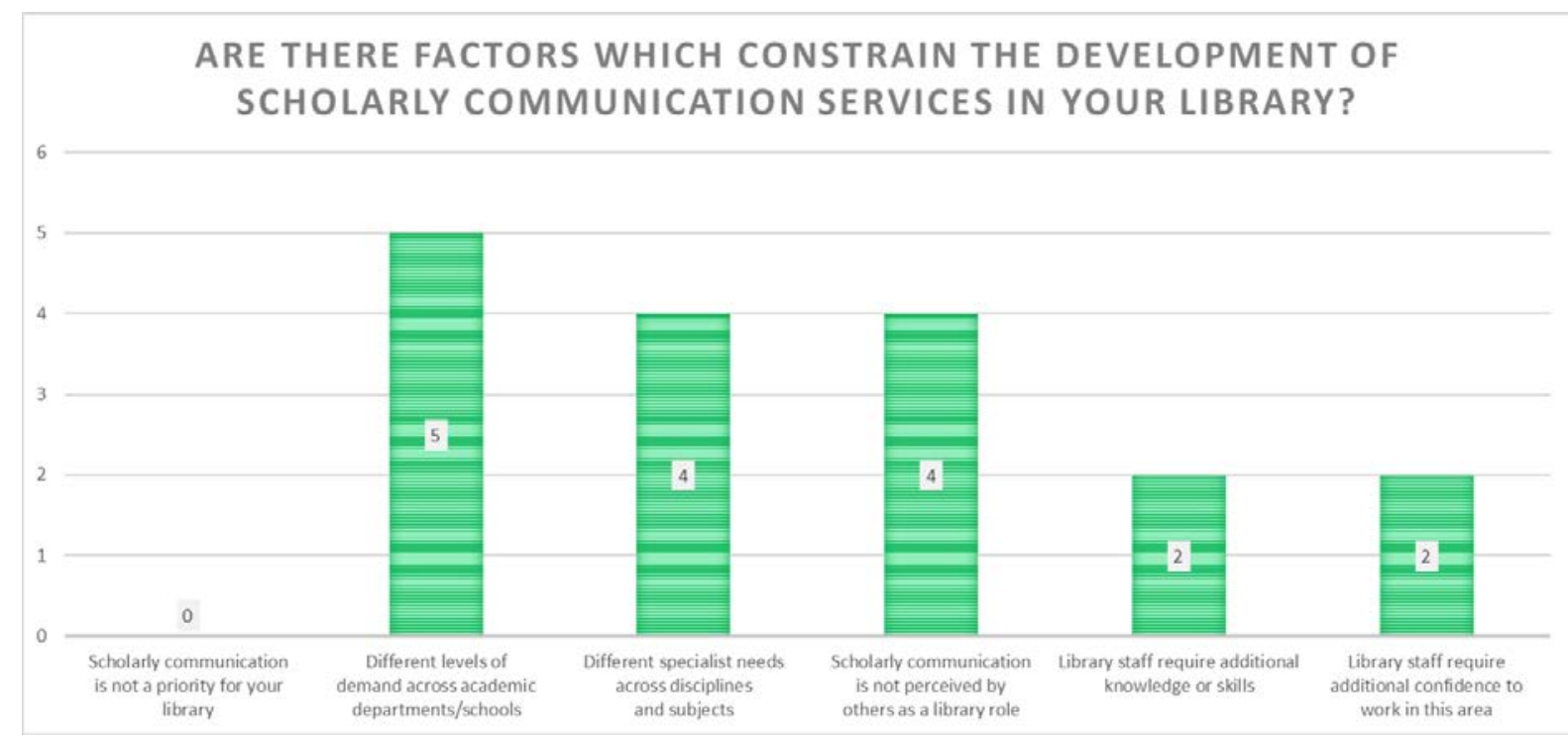

Figure 12 Barriers to scholarly communication services

Interestingly, no respondent indicated that scholarly communication was not a priority for their library, thereby reaffirming that libraries regard themselves as natural scholarly communication advisors. However, this affirmation is challenged by half of respondents reporting a lack of perception on the part of others that scholarly communication is a library role. This finding supports the Ithaka survey results (Ithaka S+R, 2018), and confirms the need for advocacy and outreach. The biggest constraining factor was differing levels of demand across academic departments and schools, followed closely by different specialist needs across disciplines and subjects. So it would seem that demand is fragmented across most institutions.

\section{IF LIBRARY STAFF REQUIRE ADDITIONAL KNOWLEDGE OR SKILLS \\ TO OFFER SCHOLARLY COMMUNICATION SERVICES, WHICH SPECIFIC AREAS NEED DEVELOPMENT?}

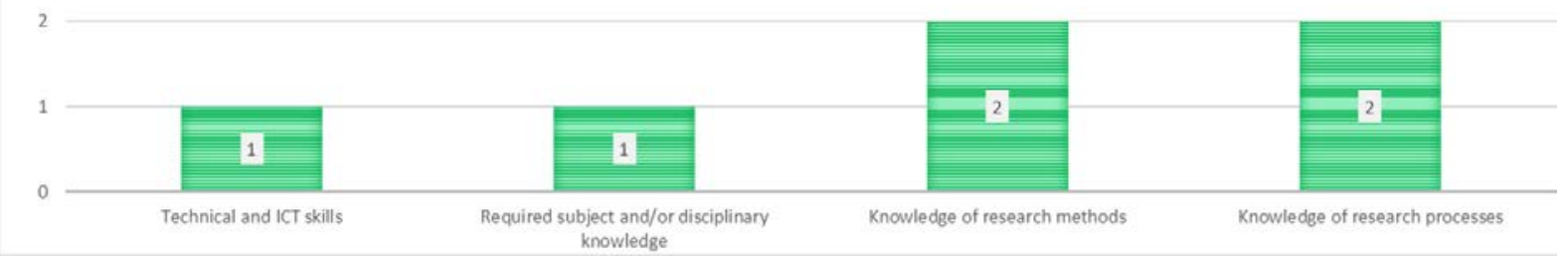

Figure 13 Scholarly communication services and staff skills 
Judging by the fact that no skill set was reported as missing by more than two institutions, it appears that capacity for supporting scholarly communication is at a reasonably good level across New Zealand university libraries. Knowledge of research methods and processes were potential areas of growth, reinforcing the need for librarians to acquire and demonstrate a good understanding, if not hands-on experience, of research.

\section{Kaupapa Māori research support services}

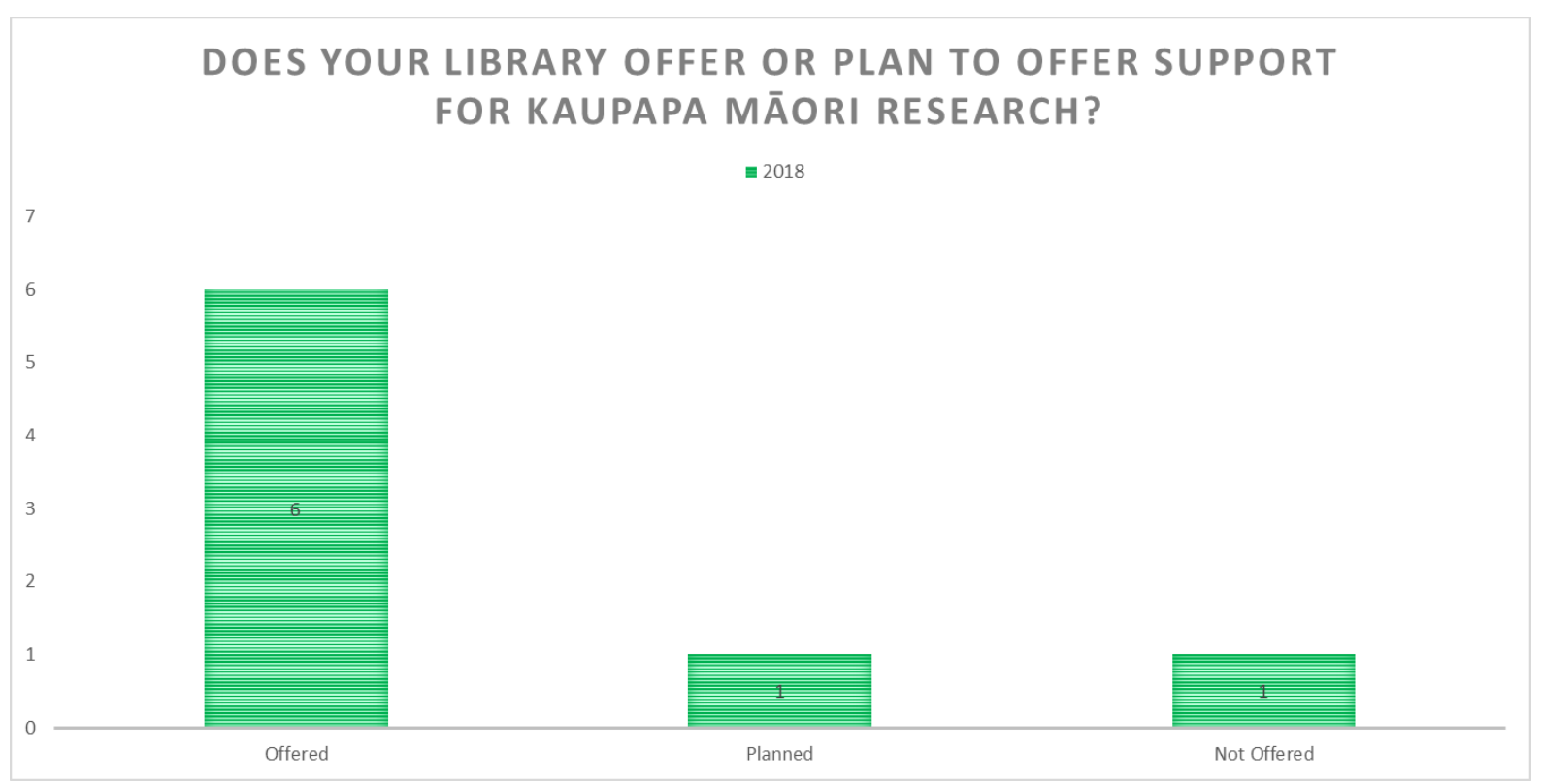

Figure 14 Services supporting Kaupapa Māori research

For the purposes of the survey, Kaupapa Māori research was defined as 'Research that seeks to identify and uphold a Māori worldview, solutions and ways of knowing with outcomes that support Māori'. Nevertheless, it’s hard to know exactly how each institution defines Kaupapa Māori research in practice, which would give context to the validity of the data portrayed in Figure 14. We suspect the generic definition, meaning any research with a Māori topic, instead of the more inclusive, research by, for, about and with Māori may have been applied. Surprisingly, given institutions have obligations to the Treaty of Waitangi - a founding document of New Zealand - and despite each university indicating the presence of one or more Māori librarian positions, only six libraries currently offer research support services for 
Kaupapa Māori research. The varying definitions of Kaupapa Māori research may be impacting the responses to this question, but this only reaffirms the notion that Libraries need to develop an understanding of their role in the Kaupapa Māori research space.

As this is the first survey of this kind, the question of factors constraining the development of Kaupapa Māori research support was left open. One survey respondent, responded by saying 'perceptions that the Library does not have a major role in the area' (Survey Respondent). This highlights the need for Libraries to 1) rethink the approach to meeting the needs of Kaupapa Māori research, 2) identify ways of being more visible in the Kaupapa Māori research space and 3) consider a new approach for recruiting and retaining Māori staff in the Library profession. However, financial investment in staff and resources as well as the organisational governance infrastructure will be central to the institutional change required to support and uphold authentic/genuine Kaupapa Māori research.

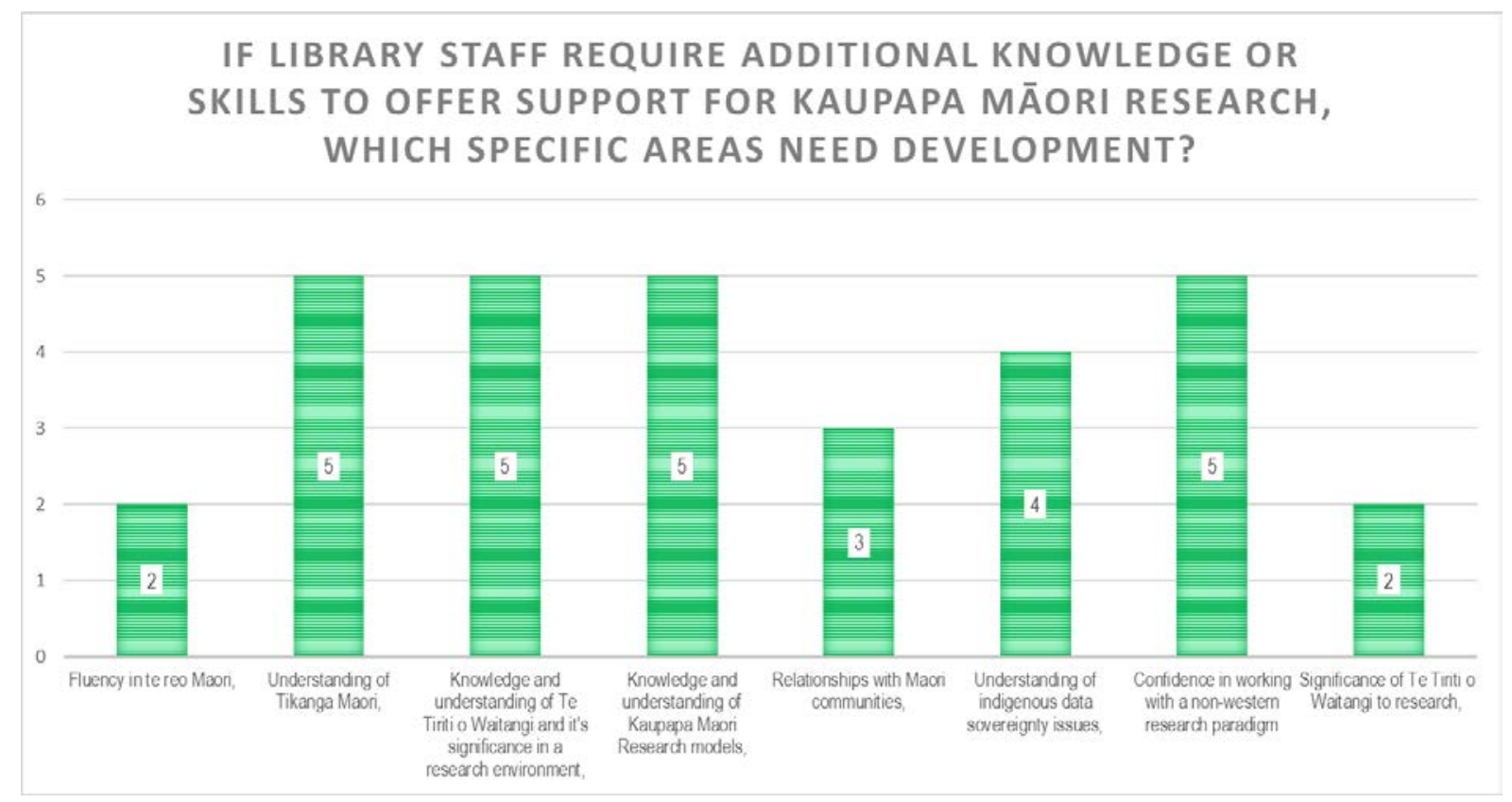

Figure 15 Services supporting Kaupapa Māori research and staff skills

When asked what factors constrain the development of support for Kaupapa Māori research, the majority of responses indicated resourcing, followed closely by the institution's inability to attract applicants to Māori library positions. This means that libraries are either recruiting 
people who require significant knowledge and skills development, or, they are needing to develop their current library staff. Either scenario supports the above findings, that significant knowledge and skills development is required in order for university libraries to adequately meet the support needs of Kaupapa Māori research. Surprisingly, only two respondents identified fluency in te reo Māori language as an additional knowledge or skill requirement. Either this means that the other respondents already have fluent te reo speaking Library staff, or, more possibly, they don't identify te reo as an integral part of Kaupapa Māori research. Language,though is culturally loaded. For example, whenua can simply mean land or a more nuanced interpretation in te reo Māori would afterbirth/placenta. The use of te reo brings with it inherent concepts, ideas and worldviews and can take research - given its holistic nature, to a place that English language cannot.

\section{Demand and future services}

At the conclusion of the survey, respondents were invited to comment on unmet demand for research support services and future plans for services not covered in the survey. The most frequently identified unmet demand was hands-on training for tools and technologies - NVivo, Research Data Management and bibliometric analytics were mentioned by name. On the horizon for New Zealand university libraries are the establishment and formalisation of collaborative groups, support for digital humanities, expansion of research intelligence and consideration for data repositories. The need for discipline-specific support was noted, as was the need for staff who specialised in research support. The tensions involved in resourcing this in a financially-constrained environment were also mentioned. The potential need for staff reallocation was acknowledged, but so was the natural synergy between the skills of existing staff and the emerging areas of demand, for example, between preservation work and Research Data Management. 


\section{Discussion}

Academic librarians must identify ways in which they can add value in the evolving scholarly landscape. Building a workforce that will be responsive to opportunities arising from the changes in the research environment and sensitive to the New Zealand context will be key in the future.

This research showed development in many areas. Services in the research impact and Research Data Management spaces showed evidence of expansion and scholarly communication services appear to have attained a sustainable level of maturity despite the recent emergence of the field. The closing of skills gaps is widely evident, but a lack of consistency was revealed, with roles varying widely and disparity in demand across disciplines remaining problematic, which reflects the Australian experience (Haddow \& Mamtora, 2017). While it is positive to see an overall increase in collaboration with other units, there is considerable potential yet to be realised. As other units with universities begin to offer these services it will become increasingly important to collaborate and pool resources, in order to avoid the undesirability of duplication or competition. This supports the arguments of Auckland (2012), Bladek (2014) and Haddow (2014). For example, low levels of technical support were reported in the RDM space, consistent with the findings of others (Cox, Kennan, et al., 2017; Hua et al., 2015; Tenopir et al., 2014), alongside increasing involvement by computing and ITS units. Both units have considerable value to offer, and it is important that efforts are made to align services and deliver support that is comprehensive, practical and culturally-sensitive.

Three main areas of concern emerged from the responses; lack of resourcing, lack of awareness and inability to recruit people with the required specialist skill set. In considering the identified barrier of lack of resourcing, we need to be realistic and responsible in the way that services are developed in a financially constrained environment. New areas of service need to be 
sustainable, and underpinned by appropriate training and support. Just as excellent research needs resourcing, so too does excellent research support. Without a realistic level of investment from parent institutions, a risk of failure arises through unmanageable workloads, low quality or poorly-informed service and staff burnout born from the need to be 'Jack of all trades and master of none'. Libraries are not only rationalising existing services to make new ones, but are also finding additional savings in line with the current economic climate. This may be a good time to consider how any tangible contribution the library makes to the research success of its institution may be appropriately recognised and rewarded. For example, Borrego et al. (2018) argued for co-authorship as a way to acknowledge contribution, while Jaguszewski and Williams (2013) see this as largely aspirational. Perhaps library objectives need to be linked to funding, for example, degree completions. Another area of concern was a lack of awareness on the part of the wider university that the library has a role in these areas. Libraries need to demonstrate their unique qualifications to be key players in research support. For example, the fact that a librarian's expertise with metrics stems from collection management rather than research assessment could mean theirs will be an important voice for speaking to responsible metrics use.

Finally, it is clear that attracting and retaining staff with the capacity to support Kaupapa Māori research is problematic. Despite removing perceived barriers such as strict qualification requirements and the existence of Te Rōpū Whakahau (Māori engaged in Libraries, Culture, Knowledge, Information, Communication and Systems Technology in Aotearoa New Zealand), the number of Māori librarians remain low. Of the approximately 4,000 New Zealanders who identified as librarians in the 2013 census only 294 were of Māori decent (Statistics New Zealand, 2013). And yet the literature reminds us how important culturally appropriate support is to the success of Māori researchers, including students. Cooper (2018), for example, reported that as well as making the Library space more welcoming, language is 'integral to knowledge 
formation and is a carrier of culture and worldviews' (p. 15). It's difficult to ascertain the reasons for low recruitment and retention of Māori staff without more in-depth qualitative research. However, in light of the low levels of pay relative to other professions and the long held lack of diversity in the Library profession in general, it's not difficult to see why Library work is not attractive to Māori. Another possible deterrent is the pressure that comes with being representative of a cultural minority in a western institution Māori librarians are often heavily burdened with the expectation that they will advocate for Māori across a wide range of platforms and issues. These factors, coupled with the perception of constrained resources, mean that libraries do not hold a great deal of mana. Mana is a Māori concept that can be understood variously as prestige, recognition or status. Perhaps the answer to robust support for Kaupapa Māori research lies in the mana of libraries themselves.

\section{Conclusion}

This research has shown that despite strong development, there is still considerable work to do before New Zealand university libraries can fully realise their potential in the research support space. By partnering with other units across their institutions, structuring and resourcing their librarians in culturally appropriate ways and positioning themselves as legitimate research partners, university libraries in New Zealand and across the world, have the power to be change agents within their organisations. From this position, they can advocate for scholarly ecosystems that deliver value to their communities, to drive initiatives that disentangle academia from proprietary systems, and empower researchers to do the same.

Though this research was able to track progress on some themes, it is intended as a starting point for discussion. The survey provided limited opportunities to elaborate on answers, and qualitative research such as that conducted by Haddow and Mamtora (2017) is needed to lend 
the results the kind of rich data that can yield a more nuanced insight into the research support landscape. Of particular value would be the voices of practitioners, given that the responses to this survey were largely limited to those with oversight and might not reflect the reality of services "on the frontline”. The sections on scholarly communication and Kaupapa Māori research are new, so future iterations will need to be carried out in order to guage progress in these areas. Finally, further research is desperately needed to explore how libraries can best recruit and retain librarians with the capacity to support and enrich Kaupapa Māori research.

The New Zealand research landscape is currently in flux - librarians need to be poised and ready to respond to environmental change. In this dynamic and politically influenced environment, librarians need to be ready to leverage their positions of trust, as 'safe harbours' from judgement (Parker, 2012, p. 12) and to do so in an academically, culturally and morally responsible way. As Mamtora (2013) puts it, 'in a sea of choice, librarians have to become islands worth visiting' (p.359).

Word count $-5,939$ 


\section{References}

Auckland, M. (2012). Re-skilling for research. Retrieved from http://www.rluk.ac.uk/wpcontent/uploads/2014/02/RLUK-Re-skilling.pdf

Bladek, M. (2014). Bibilometrics services and the academic library: Meeting the emerging needs of the campus community. College \& Undergraduate Libraries, 21(3-4), 330344. https://doi.org/10.1080/10691316.2014.929066

Borrego, Á., Ardanuy, J., \& Urbano, C. (2018). Librarians as research partners: Their contribution to the scholarly endeavour beyond library and information science. The Journal of Academic Librarianship, 44(5), 663-670. https://doi.org/10.1016/j.acalib.2018.07.012

Brown, R. A., Wolski, M., \& Richardson, J. (2015). Developing new skills for research support librarians. Australian Library Journal, 64(3), 224-234. https://doi.org/10.1080/00049670.2015.1041215

Cooper, D., Ball, T., Boyer-Kelly, M. N., Carr-Wiggin, A., Cornelius, C., Cox, J. W., . . Wong, D. (2019). When research is relational: Supporting the research practices of Indigenous studies scholars. Retrieved from https://sr.ithaka.org/publications/supporting-the-research-practices-of-indigenousstudies-scholars/

Corrall, S., Kennan, M. A., \& Afzal, W. (2013). Bibliometrics and research data management services: Emerging trends in library support for research. Library Trends, 61(3), 636674. https://doi.org/10.1353/lib.2013.0005

Cox, A., Gadd, E., Petersohn, S., \& Sbaffi, L. (2017). Competencies for bibliometrics. Journal of Librarianship and Information Science, 51(3), 1-17. https://doi.org/10.1177/0961000617728111 
Cox, A. M., Kennan, M. A., Lyon, L., \& Pinfield, S. (2017). Developments in research data management in academic libraries: Towards an understanding of research data service maturity. Journal of the Association for Information Science and Technology, 68(9), 2182-2200. https://doi.org/10.1002/asi.23781

Cox, A. M., \& Pinfield, S. (2013). Research data management and libraries: Current activities and future priorities. Journal of Librarianship and Information Science, 46(4), 299316. https://doi.org/10.1177/0961000613492542

Faniel, I., \& Connaway, L. (2018). Librarians' perspectives on the factors influencing research data management programs. College \& Research Libraries, 79(1), 100-119. https://doi.org/10.5860/crl.79.1.100

Gorraiz, J., Wieland, M., \& Gumpenberger, C. (2012). Bibliometric practices and activities at the University of Vienna. Library Management, 33(3), 174-183. https://doi.org/10.1108/01435121211217199

Green, J. A., Nicholls, N. H., Sferdean, F. C., \& Akers, K. G. (2014). Building support for research data management: Biographies of eight research universities. International Journal of Digital Curation, 9(2), 171-191. https://doi.org/10.2218/ijdc.v9i2.327

Haddow, G. (2012). Research support in a research assessment environment: The experience of ‘new’ universities. Library \& Information Science Research, 36(113), 62-80.

Haddow, G., \& Mamtora, J. (2017). Research support in Australian academic libraries: Services, resources, and relationships. New Review of Academic Librarianship, 23(23), 89-109. https://doi.org/10.1080/13614533.2017.1318765

Hashim, A. M., \& Abdullah, A. (2015, August). Embedded librarianship in scholarly communication: Perceived roles of academic librarians in Malaysian research intensive universities. Paper presented at the International Conference on Libraries, Penang, Malaysia. Retrieved from 
http://myrepositori.pnm.gov.my/bitstream/123456789/4348/1/ICOL2015_Session3_P aper1.pdf

Hua, X., Zhuang, X., Si, L., Zhou, L., \& Xing, W. (2015). Investigation and analysis of research data services in university libraries. The Electronic Library, 33(3), 417-449. https://doi.org/10.1108/EL-07-2013-0130

Ithaka S+R. (2018). CONZUL faculty survey: Aggregate report of findings.

Jaguszewski, J. M., \& Williams, K. (2013). New roles for new times: Transforming liaison roles in research libraries. Retrieved from https://conservancy.umn.edu/bitstream/handle/11299/169867/TransformingLiaisonRo les.pdf?sequence $=1 \&$ isAllowed $=\mathrm{y}$

Keller, A. (2015). Research support in Australian university libraries: An outsider view. Australian Academic \& Research Libraries, 46(2), 73-85. https://doi.org/10.1080/00048623.2015.1009528

Kennan, M. A., Corrall, S., \& Afzal, W. (2014). “Making space” in practice and education: Research support services in academic libraries. Library Management, 35(8/9), 666683. https://doi.org/10.1108/LM-03-2014-0037

Koltay, T. (2017). Research 2.0 and research data services in academic and research libraries: Priority issues. Library Management, 38(6/7), 345-353. https://doi.org/10.1108/lm11-2016-0082

Koltay, T. (2019). Accepted and emerging roles of academic libraries in supporting Research 2.0. The Journal of Academic Librarianship, 45(2), 75-80. https://doi.org/10.1016/j.acalib.2019.01.001

Lang, L., Wilson, T., Wilson, K., \& Kirkpatrick, A. (2018). Research support at the crossroads: Capability, capacity, and collaboration. New Review of Academic Librarianship, 1-11. https://doi.org/10.1080/13614533.2018.1460727 
Mamtora, J. (2013). Transforming library research services: towards a collaborative partnership. Library Management, 34(4-5), 352-371. https://doi.org/10.1108/01435121311328690

McAllister, T. G., Kidman, J., Rowley, O., \& Theordore, R. F. (2019). Why isn’t my professor Māori? A snapshot of the academic workforce in New Zealand universities. MAI Journal: A New Zealand Journal of Indigenous Scholarship, 8(2) https://doi.org/10.20507/MAIJournal.2019.8.2.10

McNab, A., \& Tattersall, A. (2017, September). The digital transformation of research support. Paper presented at the Northern Collaboration, York, United Kingdom Ministry of Research Science and Technology. (2007). Vision Matauranga. Retrieved from http://www.mbie.govt.nz/info-services/science-innovation/agencies-policies-budgetinitiatives/vm-booklet.pdf

Parker, R. (2012. What the library did next: Strengthening our visibility in research support. Paper presented at the VALA - Libraries, Technology and the Future Conference, Melbourne, Australia. Retrieved from https://www.vala.org.au/vala2012proceedings/vala2012-session-1-parker/\#

Petersohn, S. (2014, October). Bibliometric services in research evaluation: A new task area strengthening the jurisdiction of academic librarians. Paper presented at the International Association of Tertiary and University Libraries Conference, Helsinki, Finland. Retrieved from http://docs.lib.purdue.edu/iatul/2014/performance/1

Petersohn, S., \& Heinze, T. (2017). Professionalization of bibliometric research assessment. Insights from the history of the Leiden Centre for Science and Technology Studies (CWTS). Science and Public Policy, 45(4), 565-578.

https://doi.org/10.1093/scipol/scx084 
Primary Research Group. (2017). International survey of research university faculty: Use of library assistance in navigating bibliometrics \& altmetrics tools.

Roa, T., Beggs, J. R., Williams, J., \& Moller, H. (2009). New Zealand’s Performance Based Research Funding (PBRF) model undermines Māori research. Journal of the Royal Society of New Zealand, 39(4), 233-238.

Smith, L. T. (2012). Decolonizing methodologies: Research and indigenous peoples. London, United Kingdom: Zed Books.

Statistics New Zealand. (2013). Employment ethnicity 2013 census data [Data file]. Retrieved from Statistics New Zealand.

Statistics New Zealand. (2017). Research and development survey. Retrieved from https://www.stats.govt.nz/information-releases/research-and-development-survey2016Te Mana Rauranga. (2016). Te Mana Rauranga - Māori Data Sovereignty Network Charter. Retrieved from http://planetmaori.com/Files/Content/2016/Te_Mana_Raraunga_Charter.pdf

Tenopir, C., Sandusky, R. J., Allard, S., \& Birch, B. (2014). Research data management services in academic research libraries and perceptions of librarians. Library \& Information Science Research, 36(2), 84-90. https://doi.org/10.1016/j.lisr.2013.11.003

Tenopir, C., Talja, S., Horstmann, W., Late, E., Hughes, D., Pollock, D., . . . Allard, S. (2017). Research data services in European academic research libraries. Liber Quarterly, 27(1), 23-44. https://doi.org/10.18352/lq.10180

Tertiary Education Commission. (2019). Performance-Based Research Fund. Retrieved from https://www.tec.govt.nz/funding/funding-and-performance/funding/fundfinder/performance-based-research-fund/

Wilkinson, M., Amos, H., Morton, L., Flaherty, B., Hearne, S., Lynch, H., . . Elliot, G. (2016). Research data management framework report. CONZUL Working Group. 
Retrieved from http://www.universitiesnz.ac.nz/files/CONZUL-

RDM\%20Framework\%20Report\%202015\%20FINAL.pdf

Willson, M. A., Merrick, H., \& Genoni, P. (2006). Scholarly communities, e-research literacy and the academic librarian. The Electronic Library, 24(6), 734-746. https://doi.org/10.1108/02640470610714189

Wilson, J., Martinez-Uribe, L., Fraser, M., \& Jeffreys, P. (2011). An institutional approach to developing research data management infrastructure. The International Journal of Digital Curation, 6(2), 274-287.

Zhao, L. (2014). Riding the wave of Open Access: Providing library research support for scholarly publishing literacy. Australian Academic \& Research Libraries, 45(1), 3-18. https://doi.org/10.1080/00048623.2014.882873 
Start of Block: Research Impact

Thank you for taking time to participate in this survey. The purpose of this survey is to investigate the nature and extent of research support services in New Zealand University Libraries. It will also explore the factors influencing the development and delivery of these services. The four main focuses are services relating to research impact, research data management, scholarly communication and Kaupapa Māori Research. For each of these areas we hope to ascertain what level of services are being offered, or are planned, how those services are being developed, and what barriers and skill gaps might inhibit the development of the services. Parts of this survey are based on two prior studies - Haddow and Mamtora (2017), which focussed on Australian Universities, and Corrall, Kennan and Afzal (2012), whose global sample included both Australia and New Zealand. For those questions common with Haddow and Mamtora (2017), we hope to be able to benchmark against service offerings in Australia. For those questions that are common with Corrall, Kennan and Afzal (2012), we hope to be able to identify changes in New Zealand University Library services since 2012. It is hoped the results as a whole will act as a snapshot of the research support landscape in New Zealand, and provide a basis for future research, as well as informing decisions around future directions. These questions concern services aimed mainly at academic staff/researchers, but may also be offered to research students. The survey should take no longer than 20 minutes to complete. Your name, location and institution will not be recorded and any identifying data will be anonymised. The resulting research may be published in academic or professional journals, or presented at conferences. This project has been reviewed and approved by the University of Waikato Human Ethics Committee, reference number HREC2018\#06. If you have any concerns about the conduct of this research, please contact Dr Karsten 
Zegwaard, Acting Chair, University of Waikato Human Research Ethics Committee, humanethics@waikato.ac.nz._For any questions about the research, please contact: Jess Howie Phone: 078384762 Email: j.howie@waikato.ac.nz By ticking "yes" below and continuing to the next page you are indicating your voluntary consent to participate.

Do you consent to the above?

Yes (1)

No (2) 
Q1 Does your library offer or plan to offer any of the following research impact services?

\begin{tabular}{|c|c|c|c|}
\hline & Offered (1) & Planned (2) & Not Planned (3) \\
\hline $\begin{array}{l}\text { Bibliometrics } \\
\text { training/bibliometrics } \\
\text { literacy (1) }\end{array}$ & & & \\
\hline Citation reports (2) & & & \\
\hline $\begin{array}{l}\text { Calculations of } \\
\text { Research Impact (3) }\end{array}$ & & & \\
\hline Grant applications (4) & & & \\
\hline $\begin{array}{l}\text { Disciplinary research } \\
\text { trend reports (5) }\end{array}$ & & & \\
\hline $\begin{array}{l}\text { Altmetrics } \\
\text { training/literacy (6) }\end{array}$ & & & \\
\hline Altmetrics reports (7) & & & \\
\hline $\begin{array}{l}\text { H-index calculations } \\
\text { (8) }\end{array}$ & & & \\
\hline Other (9) & & & \\
\hline
\end{tabular}


Q2 Does the library partner with any other units within the university to offer research impact services?

No (1)

Yes (please type which units and services in the text box) (2)

Q3 Do any units within the university other than the library offer research impact services?

Yes - Research Office (or equivalent) (1)

Yes - Academic Services (or equivalent) (2)

No (3)

Other (4)

Q4 What are the job titles of the people who provide research impact services, in the library or other in other units? Please state service/unit, if not in the library. 
Q5 What number of library staff are involved in providing research impact services? And what percentage of their time, on average, would be devoted to these services?

Q6 What are the barriers which hinder the development of research impact services in your library? Please select ALL that apply

Research impact is not a priority for your library (1)

Research impact is not a priority for your university (2)

Research impact is not perceived by others as a library role (3)

Different level of demand across academic departments/schools (4)

There are different specialist needs across disciplines and subjects (5)

Library staff require additional knowledge or skills (6)

Library staff require additional confidence to work in this area (7)

Other (8) 
Q7 If library staff require additional knowledge or skills to offer research impact services, which specific areas need development? Please select ALL that apply.

Knowledge of different purposes and applications of bibliometrics (e.g. research evaluation, collection development, benchmarking) (1)

Skills in quantitative methods and statistics (2)

Knowledge of bibliometrics tools and techniques (e.g. citation analyses, impact factors and associated indices) (3)

Required subject and/or disciplinary knowledge (4)

Other (5) 
Q8 Does your library offer, or plan to offer, any of the following research data services? Please select all that apply. 
Assisting researchers to use available technology,

infrastructure and tools (1)

Guidance on the handling and management of unpublished research data, for example data literacy education and/or training (2)

Support for data deposit in an institutional repository (3)

Support for data deposit in external repositories or data archives (4)

Finding relevant external data sets (5)

Technical aspects of digital curation (6)

Developing data management plans (7)

Developing tools to assist researchers manage their data (8)

Development of institutional policy to manage research data (9) 
Please expand on the services you provide if not adequately captured in the descriptions here OR state other services if not included above.

(10)

Q9 Does your institution have a university-wide policy on the retention and sharing of research data?

Yes (if publicly available, please copy and paste URL here) (1)

No (2)

Under development (3) 
Q10 Does the library partner with any other units within the university to offer research data services?

Yes (please type which units and services in the text box) (1)

No (2)

Planned (please type which units and services in the text box) (3)

Q11 Do any units within the university OTHER than the library offer research data management services? Please select ALL that apply

Yes - Research Office (1)

Yes - Computing or Information Technology Services (2)

Yes - Academic Services (3)

No (4)

Other (5) 
Q12 What are the job titles of the people who provide research data services, in the library or in other units? Please state the service/unit, if not in the library

Q13 How many library staff are involved in providing research data services? What percentage of their time, on average, is devoted to these services? 
Q14 Are there factors which constrain the development of research data management services in your library? Please select ALL that apply

Research data management is not a priority for your library (1)

Different levels of demand across academic departments/schools (2)

Different specialist needs across disciplines and subjects (3)

Research data management is not perceived by others as a library role (4)

Library staff require additional knowledge or skills (5)

Library staff require additional confidence to work in this area (6)

Other (7) 
Q15 If library staff require additional knowledge or skills to offer research data management services, which specific areas need development? Please select ALL that apply

Data curation skills (1)

Technical and ICT skills (2)

Required subject and/or disciplinary knowledge (3)

Knowledge of research methods (4)

Knowledge of research processes (5)

Other (6) 
Q17 Does your library offer or plan to offer any of the following scholarly communication services?

\begin{tabular}{l|l|l} 
& Offered (1) Planned (2) & Not Planned (3) \\
Publishing advice (1) & \\
Promoting research & \\
(2) & \\
Social media for \\
research meting \\
dissemination (3)
\end{tabular}


Q18 Does the library partner with any other units within the university to offer scholarly communication services?

Yes (please type which units and services in the text box) (1)

No (2)

Planned (please type which units and services in the text box) (3)

Q19 Do any units within the university OTHER than the library offer scholarly communication services? Please select ALL that apply

No (1)

Yes - Research Office (or equivalent) (2)

Yes - Computing or Information Technology Services (or equivalent) (3)

Yes - Academic Services (or equivalent) (4)

Other (5) 
Q20 What are the job titles of the people who provide scholarly communication services, in the library or in other units? Please state the service/unit, if not in the library

Q21 How many library staff are involved in providing scholarly communication services? What percentage of their time, on average, is devoted to these services? 
Q22 Are there factors which constrain the development of scholarly communication services in your library? Please select ALL that apply

Scholarly communication is not a priority for your library (1)

Different levels of demand across academic departments/schools (2)

Different specialist needs across disciplines and subjects (3)

Scholarly communication is not perceived by others as a library role (4)

Library staff require additional knowledge or skills (5)

Library staff require additional confidence to work in this area (6)

Other (7) 
Q23 If library staff require additional knowledge or skills to offer scholarly communication services, which specific areas need development? Please select ALL that apply

Technical and ICT skills (1)

Required subject and/or disciplinary knowledge (2)

Knowledge of research methods (3)

Knowledge of research processes (4)

Other (5)

\section{End of Block: Scholarly Communication}

Start of Block: Kaupapa Maori Research

Q35

The next portion of the survey focusses on support for Kaupapa Maori Research For the purposes of this survey, Kaupapa Maori Research is defined as "Research that seeks to identify and uphold a Māori worldview, solutions and ways of knowing with outcomes that support Māori." These questions concern services aimed mainly at academic staff/researchers, but may also be offered to research students. 
Q24 What services does your library offer or plan to offer to support for Kaupapa Maori Research?

Q25 Do any units within the university other than the library offer support for Kaupapa Maori research?

Yes - Research Office (or equivalent) (1)

Yes - Academic Services (or equivalent) (2)

No (3)

Other (4)

Q26 What are the job titles of the people who provide support for Kaupapa Maori research, in the library or in other units? Please state the service/unit, if not in the library 
Q27 How many library staff are involved in providing support for Kaupapa Maori research? What percentage of their time, on average, is devoted to this provision?

Q28 Are there factors which constrain the development of support for Kaupapa Maori research in your library? If so, please list them here 
Q29 If library staff require additional knowledge or skills to offer support for Kaupapa Maori research, which specific areas need development? Please select ALL that apply

Fluency in Te Reo Maori (1)

Understanding of Tikanga Maori (2)

Knowledge and understanding of Te Tiriti o Waitangi and it's significance in a research environment (3)

Knowledge and understanding of Kaupapa Maori Research models (4)

Relationships with Maori communities (5)

Understanding of indigenous data sovereignty issues (6)

Confidence in working with a non-western research paradigm (7)

Other (8)

\section{End of Block: Kaupapa Maori Research}

Start of Block: Summary

Q32 Are you experiencing demand for research support services that are not currently offered by the library? If so, briefly list them here 
Q33 If your library is planning or considering any additional bibliometrics, research data or other new research support services, please list them here

Q34 Do you have any other comments on library provision of research support services? 


\section{Table of figures}

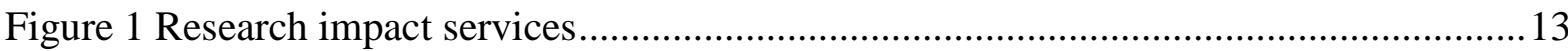

Figure 2 Research impact service partners ....................................................................... 14

Figure 3 Barriers to research impact services ...................................................................15

Figure 4 Research impact services and staff skills ............................................................16

Figure 5 Research Data Management services .................................................................17

Figure 6 Research Data Management service partners .....................................................18

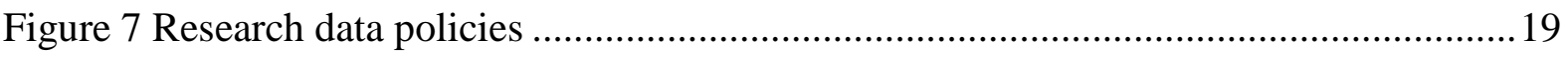

Figure 8 Barriers to Research Data Management services ................................................19

Figure 9 Research Data Management services and staff skills...........................................20

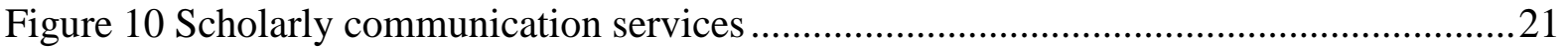

Figure 11 Scholarly communication service partners....................................................22

Figure 12 Barriers to scholarly communication services..................................................23

Figure 13 Scholarly communication services and staff skills.............................................23

Figure 14 Services supporting Kaupapa Māori research .....................................................24

Figure 15 Services supporting Kaupapa Māori research and staff skills...............................25 